\title{
Nutrients in Alzheimer's Disease: The Interaction of Diet, Drugs and Disease
}

\author{
S. Imindu Liyanage, Prachi Vilekar, Donald F. Weaver
}

\begin{abstract}
In recent decades, clinical trials in Alzheimer's disease (AD) have failed at an unprecedented rate. The etiology of AD has since come under renewed scrutiny, both to elucidate the underlying pathologies and to identify novel therapeutic strategies. Here, diet has emerged as a potential causative/protective agent. A variety of nutrients, including lipids, minerals, vitamins, antioxidants and sugars as well as broader dietary patterns and microbiotal interactions have demonstrated associations with AD. Although clinical trials have yet to definitively implicate any singular dietary element as therapeutic or causative, it is apparent that dietary preferences, likely in complex synergies, may influence the risk, onset and course of AD. This review catalogs the impact of major dietary elements on AD. It further examines an unexplored reciprocal association where AD may modulate diet, as well as how potential therapeutics may complicate these interactions. In doing so, we observe diet may have profound effects on the outcome of a clinical trial, either as a confounder of a drug/ disease interaction or as a generally disruptive covariate. We therefore conclude that future clinical trials in AD should endeavor to control for diet, either in study design or subsequent analyses.
\end{abstract}

RÉSUMÉ: Les interactions entre l'alimentation et la prise de médicaments dans le cas de la maladie d'Alzheimer. Au cours des dernières décennies, les essais cliniques liés à la maladie d'Alzheimer (MA) ont échoué à un rythme sans précédent. Depuis, l'étiologie de cette maladie a fait l'objet d'un examen plus attentif à la fois pour mieux comprendre les troubles sous-jacents de la MA et pour identifier de nouvelles stratégies thérapeutiques. À cet égard, l'alimentation est apparue au fil des années comme un agent potentiellement causal/protecteur dans le cas de la MA. On a ainsi pu démontrer qu'une variété de nutriments, ce qui inclut des lipides, des minéraux, des vitamines, des antioxydants et des sucres, de même que des habitudes alimentaires plus variées et des interactions propres à la flore intestinale, pouvaient être associées à l'évolution de la MA. Bien que l'on doive encore établir de façon définitive au moyen d'essais cliniques le rôle causal et thérapeutique de quelque élément nutritif que ce soit, il est clair que les choix alimentaires que l'on fait, probablement dans le cadre de synergies complexes, pourraient avoir une influence sur le risque d'être atteint de la MA, sur son apparition et son évolution. Cette étude entend donc se pencher sur l'impact des principaux éléments nutritifs en ce qui a trait à la MA. Elle examinera en outre les associations réciproques peu abordées en vertu desquelles il est possible que la MA ait un impact sur l'alimentation; elle cherchera aussi à savoir dans quelle mesure d'éventuelles options thérapeutiques peuvent affecter ces interactions. Ce faisant, nous sommes d'avis que l'alimentation pourrait avoir de profonds effets sur les résultats d'essais cliniques, que ce soit à titre d'élément perturbant les interactions entre un médicament et la maladie ou, le plus souvent, à titre de covariable perturbatrice. En somme, nous sommes amenés à conclure que les essais cliniques du futur portant sur la MA devraient s'efforcer de tenir compte de l'alimentation, que ce soit dans leur méthodologie ou lors d'analyses ultérieures.

Keywords: Alzheimer's disease, Diet, Clinical trials, Medications, Lipids, Cholesterol, Sugar, Vitamins, Minerals, Microbiota doi: $10.1017 / \operatorname{cjn} .2018 .353$

Can J Neurol Sci. 2019; 46: 23-34

\section{INTRODUCTION}

Alzheimer's disease (AD) is the most common form of dementia, ${ }^{1}$ affecting 1 in 10 North American seniors (aged $\geq 65)^{2,3}$ Although the search for a disease-modifying agent has been intense, $99.6 \%$ of compounds entering clinical trials have failed. ${ }^{4,5}$ Typically, these failures are ascribed to an inadequate understanding of the multifactorial etiology of $\mathrm{AD}$; studies have therefore urged renewed investigation of the underlying neuropathologies. However, the emerging complexity and prevalence of AD may suggest that broader systemic or environmental factors, not routinely considered in neurology, may also be relevant to the onset and outcomes of disease.

In early studies, environmental factors, like metals, toxins and diet, were thought to be the definitive causes of AD. Although the etiology has since proven more complex, this environmental hypothesis regained credence in the 1990s when studies of AD prevalence among Japanese migrants in the United States revealed rates assimilative to local populations, and significantly higher than in native Japanese. ${ }^{6}$ Similar trends were discerned among African-American and Hispanic-American populations, which cumulatively suggest a role for environment in $\mathrm{AD}$ pathogenesis. $^{7-9}$

Significant changes in AD prevalence were also emerging among static populations; of note again is Japan, which witnessed a dramatic rise in prevalence from 1985 to 2010, as

From the Krembil Research Institute, University Health Network, Toronto, ON, Canada (SIL, PV, DFW); Faculty of Medicine, University of Toronto, Toronto, ON, Canada (DFW).

Received March 19, 2018. Final Revisions Submitted August 1, 2018. Date of ACCEPTANCE August 19, 2018.

Correspondence to: Donald F. Weaver, Faculty of Medicine, University of Toronto, Toronto, ON, Canada. Email: donald.weaver@uhnresearch.ca 
reported by Grant. ${ }^{10}$ This loosely correlated with a period of westernization, in which dietary habits underwent a transformation from traditional cuisines, rich in fish and fresh vegetables, to an appreciably more North-American diet, heavier in fats and processed foods. ${ }^{11,12}$ Although purely speculative, these loose associations revived some interest in diet as a causative factor in AD.

At present, extensive studies have identified various mitigating and aggravating nutrients, in addition to regional diets and metabolic states, which may play a role in AD development and progression. This review first examines the major nutritional influences on $\mathrm{AD}$, as currently understood, and catalogs the relevant lipids, carbohydrates, vitamins, minerals and broader dietary patterns associated with AD. In addition, we observe and report on a relatively unexplored reciprocal association, wherein AD may alter dietary preference and nutritional intake. This review also considers the implications of these interactions to therapeutic agents and clinical trials. Specifically, we present an argument that the multifaceted interactions among diet, drugs and AD may be sufficient to confound or obscure the efficacy of a clinical agent in a drug trial, and suggest strategies to abate such an influence.

\section{Alzheimer's Disease Pathology}

Alzheimer's disease is characterized by three dominant neuropathologies: oligomerization of $\beta$-amyloid $(\mathrm{A} \beta)$, aggregation of tau into neurofibrillary tangles and brain atrophy. ${ }^{13}$ The etiology of these pathologies remains unclear; however, it is well established that no recognized singular dysfunction directly precedes the deposition of plaques and tangles. Rather, a complex interlay of proteopathic and immunopathic changes culminate in the observed pathologies. ${ }^{14-16}$

A $\beta$ aggregates originate from transmembrane amyloidprecursor proteins (APP). APP is typically associated with essential signaling roles in cellular physiology, ${ }^{17}$ but when cleaved by $\alpha / \gamma$-secretase or $\beta$-site APP cleaving enzyme (BACE), they can misfold and aggregate into toxic oligomers. ${ }^{18}$ This is attended by an inflammatory cascade, which causes further damage to the neural parenchyma, as well as elevate oxidative stress. ${ }^{19}$ Within neurons, AD is characterized by the accumulation of fibrillary tangles composed of microtubule-associated tau protein. ${ }^{20}$ Ordinarily, tau participates in intracellular transport and structural functions. In AD, it becomes hyper-phosphorylated and disassociates from the microtubules. Once free, tau aggregates to form a helical fiber, which impedes intracellular transport and communication. ${ }^{20}$ Together, $\mathrm{A} \beta$ and tau oligomerization lead to neuronal death and cerebral atrophy. This manifests in the deterioration of memory and cognition, as well as progressive declines of reasoning, language, and executive function. Alzheimer's disease eventually evolves to an end-stage disease, typically resulting in mortality $4-8$ years post diagnosis. ${ }^{21}$

\section{Diet And Alzheimer's Disease}

Early associations between diet and AD were assumed to be ancillary to other primary disorders, like cerebrovascular disease. However, recent data have suggested a direct role for diet in modulating oxidative stress, inflammation, synaptic plasticity, amyloidogenesis and neurogenesis-processes fundamental to AD pathogenesis ${ }^{22-24}$ and major treatment strategies. ${ }^{25-28}$ This has implicated diet as contributory in $\mathrm{AD}$, and sparked numerous nutrient-based therapeutic trials. In this section, we review the interaction of major dietary elements, both protective and detrimental, with $\mathrm{AD}$ pathologies.

\section{LiPIDS: Cholesterol AND FatTy ACIDS}

In the 1990s, a relationship between lipids and AD was suggested when mutations in the cholesterol carrier apolipoprotein $\mathrm{E}$ were identified as a major genetic predisposition for late-onset Alzheimer's. ${ }^{29,30}$ Thereafter, cholesterol was shown to have a regulatory role on the proteolytic enzymes cleaving APP, where elevated membrane cholesterol increases both $\gamma$-secretase and BACE1 activity, ultimately upregulating $\mathrm{A} \beta$ production. ${ }^{31,32}$ Cholesterol may also facilitate the aggregation of $\mathrm{A} \beta$ from its monomeric form to the neurotoxic oligomer. ${ }^{33,34}$ In a mechanistic study, Kakio et al demonstrated that cholesterol elicits the binding of $\mathrm{A} \beta$ to cellular membranes, which can then facilitate a conformational change from a helical-rich $\mathrm{A} \beta$ structure to an aggregation prone $\beta$-pleated sheet. ${ }^{35}$ Cholesterol may therefore seed the oligomerization of $\mathrm{A} \beta$ via membrane binding. ${ }^{35}$

This cholesterol hypothesis, reviewed by Liu and Zhang, ${ }^{33}$ has yielded contradictory clinical outcomes. Certain statin-based therapies, ${ }^{36,37}$ and the inhibition of cholesterol biosynthesis, ${ }^{38}$ have offered protection against $\mathrm{A} \beta$ accumulation and $\mathrm{AD}$ development. However, cholesterol is known to decrease with $\mathrm{AD}$ progression, and a gradual decline of serum cholesterol was identified as a risk factor for dementia in a large, 32-year investigation. ${ }^{39,40}$ Studies are further suggesting vital structural and functional roles for cholesterol in neurons. ${ }^{41,42}$ Consequently, as an independent therapeutic strategy for $\mathrm{AD}$, cholesterol management alone may prove challenging.

The role of fatty acids has garnered similar attention. These are among the best-studied lipids, and have shared conclusive associations to various diseases, including AD. ${ }^{33}$ Moreover, following early work by Foot et al, which demonstrated that diet can directly alter the fat composition of the brain, fatty acid management has long been purported to possess therapeutic potential. ${ }^{43}$

Dietary fats are classified by length, degree of saturation and isomerism (cis or trans). Saturated fatty acids and trans-unsaturated fatty acids have been associated with an adverse risk of AD. An observational study by Morris et al discerned that diets high in these fats could more than double the risk of $\mathrm{AD}$ over an average of 4 years. ${ }^{44}$ Unlike cholesterol, a clear interaction with AD pathologies has not been discerned. Rather, saturated and transfats have been linked to altered gene expression, elevated inflammatory signaling, disrupted metabolism, protein pathologies and higher oxidative stress, all of which have been linked to cognitive decline and behavioral changes. ${ }^{45-48}$ Prominent associations between these fats and traditional AD risk factors such as cerebrovascular disease, obesity and diabetes may also mediate the observed correlations. ${ }^{49,50}$ Although occasional studies have revealed null or insignificant associations after extended followup, ${ }^{51}$ the link between saturated and trans-fats with AD appears conclusive and detrimental.

Conversely, some polyunsaturated fatty acids (PUFAs) have revealed protective associations. Omega $(\omega)$-3 PUFAs in particular, typically obtained from fish, are associated with beneficial outcomes in both $\mathrm{AD}$ and dementia. ${ }^{52,53}$ Studies have repeatedly demonstrated that consumption of these fats (such as 
docosahexaenoic acid) are inversely associated with cognitive decline and AD. ${ }^{54-58}$ Furthermore, an exhaustive review by Cole et al identified 11 pleiotropic mechanisms by which $\omega-3$ fats may confer this protection, ranging from regulating apoptosis to diminishing local pro-inflammatory markers. ${ }^{53}$ Yet, the effect is not without contradiction, particularly among carriers of the ApoE4 allele, as well as otherwise well-nourished subjects, where no effect has been observed. ${ }^{59-63}$ Clinical trials and meta-analyses have also failed to demonstrate a significant benefit in $\mathrm{AD}$, although other cognitive parameters may be improved in unrelated cohorts. ${ }^{63,64}$

Omega-6 PUFAs, however, derived from meat, and often more abundant in a western diet, may be deleterious to an $\mathrm{AD}$ brain. ${ }^{65-67}$ Specifically, the phospholipid product of $\omega-6$ fatty acids, arachidonic acid, is implicated in upregulating inflammation and promoting $\mathrm{A} \beta$ aggregation. ${ }^{66,68}$ This claim has been occasionally disputed, and studies have suggested that a therapeutic ratio between $\omega-6$ and $\omega$-3 PUFAs may exist. Hosono et al showed that in a 2:1 dietary ratio of arachidonic acid to docosahexaenoic acid, Tg2576 mice had lower deposition of amyloid plaques and altered APP processing; ${ }^{69} \omega-6$ and $\omega-3$ fats have also been shown to preserve neural stem cells in rats. ${ }^{70}$ This suggests PUFAs may operate under a dynamic synergy. However, without further study it remains unclear whether combinations of these fats are simply confounding the observation of each other's effects, or whether there is a genuine additive association.

Broadly, cholesterol, saturated fats, trans-fats and $\omega-6$ fatty acids are likely deleterious in the context of $\mathrm{AD}$, while $\omega-3$ fatty acids have demonstrated some potential benefits. Although in all cases associations have been obscured by clinical inefficacy and contradictory findings, dietary fats may alter $\mathrm{A} \beta$ dynamics, influence neural inflammation and present numerous additional mechanisms of interaction with $\mathrm{AD}$.

\section{CARbohydrates: Sugars AND INSUlin}

High sugar and high calorie diets are well-established risk factors for dementia and $\mathrm{AD} .^{71-74}$ Further, as contributors to diabetes and other metabolic syndromes, which themselves are risk factors for $\mathrm{AD}$, the association between elevated sugar levels and Alzheimer's is strong. ${ }^{75-78}$ Paradoxically, AD-afflicted neurons are typically starved of glucose with marked reductions in glucose metabolism (up to 44\%) across brain regions most associated with AD pathology. ${ }^{79-81}$ This pattern has become so robust that topographic patterns of impaired glucose metabolism can serve as an early marker of $\mathrm{AD}$, and act as a criterion for staging progression. $^{82}$

One explanation for this apparent paradox implicates glucose transport across the blood-brain barrier (BBB). AD brains have lower levels of the glucose transporters GLUT1 and GLUT3, and therefore diminished shuttling of glucose across the BBB. ${ }^{83}$ Winkler et al demonstrated this transporter-mediated glucose starvation can aggravate $\mathrm{AD}$ neuropathologies, vascular degeneration and impair cognition. ${ }^{80,84}$ An alternative theory implicates insulin resistance for the observed glucose dysregulation. Insulin resistance occurs when tissues loose sensitivity to insulin signaling after protracted exposure, triggered by chronically elevated blood sugar. The breakdown of signaling prevents glucose from entering cells, leading simultaneously to hyperglycemia, and diminished glucose within cells. Insulin resistance has also been implicated in triggering inflammation, which may exacerbate AD pathologies. ${ }^{65}$ In addition, insulin signaling is integral to neural function, maintenance, plasticity and is increasingly associated with cognition (in the context of diabetes) all of which have been compromised when insulin signaling is perturbed. ${ }^{85-87}$ More recently, components of insulin signaling were implicated in regulating tau phosphorylation and tangling, ${ }^{88-90}$ as well as $\mathrm{A} \beta$ synthesis and degradation. ${ }^{91-93}$ This has led to speculation as to whether altered glucose metabolism may be causative in AD. Evidence of glucose dysregulation preceding clinical symptoms, as well as its high prevalence among AD cohorts provide some support for this notion. ${ }^{94}$

\section{Micronutrients: Vitamins AND Minerals}

The rise of commercial vitamins and dietary supplements reflects a growing appreciation of the importance of micronutrients in health maintenance. The accessibility of these supplements also offers a practical strategy to manage $\mathrm{AD}$ on a large scale. However, in spite of exhaustive investigations, including several well-powered clinical trials, no isolated micronutrient has yet been definitively demonstrated as an effective therapy for AD. ${ }^{95}$ Yet, deficiencies of various vitamins and minerals have been associated with an elevated risk of $\mathrm{AD}$, cognitive impairment and other dementias. ${ }^{65,95}$

The B vitamin family is critical to the metabolism of most macronutrients, including carbohydrates and lipids, and has therefore garnered some interest in the context of AD. ${ }^{96}$ Vitamin $\mathrm{B}_{1}$ or thiamine was among the first nutrients associated with dementia when it was conclusively linked to Wernicke's encephalopathy in long-term alcoholics. ${ }^{97,98}$ Earlier studies have noted conspicuous similarities between the symptoms of Wernicke's and Alzheimer's, including shared deficiencies of thiaminedependent processes, cognitive decline and aberrant glucose metabolism. ${ }^{99-101}$ In vitro studies have since shown that in a state of acute thiamine insufficiency, neurons produce markers of stress, including reactive oxygen species, and begin apoptotic processes, implying a physiologic role for thiamine in neuronal function. ${ }^{102,103}$ This has been corroborated by Zhang et $\mathrm{al}^{101}$ and others ${ }^{104}$ who demonstrated that thiamine deficiency promoted $\beta$-secretase activity, $\mathrm{A} \beta$ accumulation and oxidative stress. In clinical trials, however, thiamine supplementation has not borne significant outcomes. An early systematic review did not identify a single trial with significant positive associations between thiamine and AD. ${ }^{98}$ Koh et al also demonstrated that thiamine deficiency lost its associations with dementia when subjects were otherwise well nourished. ${ }^{105}$ This may suggest that the initial correlations were in fact between malnourishment, in which thiamine deficiency is often concomitant, and AD.

Other $\mathrm{B}$ vitamins, including pyridoxine $\left(\mathrm{B}_{6}\right)$, cobalamin $\left(B_{12}\right)$, folate $\left(B_{9}\right)$ and homocysteine, have also come under scrutiny for potential links to AD. Homocysteine is a metabolic precursor of the amino acids methionine and cysteine; however, before metabolism, homocysteine is a potent neurotoxin. ${ }^{106}$ Multiple studies have demonstrated a persistent correlation between dietary homocysteine and $\mathrm{AD}$, with physiological levels exceeding $14 \mu \mathrm{mol} / \mathrm{L}$ estimated to double the risk of AD. ${ }^{67,107-109}$ Further, in 3xTg transgenic mice, homocysteine was directly associated with cognitive decline, as well as promoting $\mathrm{A} \beta$ and tau pathologies. ${ }^{110}$ 
As an upstream metabolite, homocysteine levels do not necessarily have to be controlled by reducing dietary intake. Instead, increasing consumption of vitamins $\mathrm{B}_{6}, \mathrm{~B}_{12}$ and folate can perpetuate the conversion of homocysteine into its amino acid products. Wang et al evidenced this by demonstrating that when vitamin $\mathrm{B}_{12}$ and folate levels were impaired, subjects exhibited a higher risk of AD (over a 3-year follow-up). ${ }^{111}$ Yet, the association has been repeatedly proven insignificant and current evidence on the role of these vitamins has been deemed insufficient. ${ }^{12-114}$

Additional $\mathrm{B}$ vitamins including riboflavin $\left(\mathrm{B}_{2}\right)$ and niacin/ nicotinamide $\left(B_{3}\right)$ have also received attention owing to their metabolic roles in the brain. ${ }^{65}$ Niacin, in particular, has shown promise with high doses demonstrating some protective and even curative capacity in mouse models. ${ }^{115,116}$ Green et al demonstrated that specific phosphorylated species of tau were reduced and proteins associated with microtubule stability were elevated upon exposure to a high dose of vitamin $B_{3} .{ }^{115}$ This rescued cognition in their murine model $(3 \mathrm{xTg})$ raising the possibility of a curative treatment, rather than a typical arresting strategy. However, clinical trials have not demonstrated any tangible improvements to cognition from vitamin $\mathrm{B}_{3}$, particularly when given as supplements rather than in their natural form..$^{117,118}$ The optimal dosage of vitamins is further controversial. Studies have often examined high doses, well in-excess of established guidelines. It has been suggested that this may exceed a therapeutic benefit, if any, and potentially expose patients to toxic side effects. The excretion of supplemental vitamins may also diminish a therapeutic efficacy. As such, a re-examination of the optimal form, dose and functional levels may be required.

Nutrients with antioxidant properties have also been an area of intense study. Oxidative damage, elevated production of reactive oxygen species and impeded clearance of oxidative stress markers are well recognized in AD neurons. ${ }^{19,119,120}$ Furthermore, accumulating evidence suggests that this oxidative damage may precede the deposition of $\mathrm{A} \beta$ or tau. ${ }^{119}$ Accordingly, antioxidants have been proposed as a potential preventative and therapeutic strategy. Common dietary antioxidants include vitamin C, vitamin E, polyphenols and carotenes. ${ }^{95}$ The Cache County Study involving over 3000 participants demonstrated that in combination, vitamins $\mathrm{C}$ and $\mathrm{E}$ supplements were associated with a lower incidence of AD. ${ }^{121}$ Several other studies of comparable scope demonstrated similar associations, ${ }^{95}$ though randomized control trials have largely failed to demonstrate any therapeutic utility for antioxidants. ${ }^{122}$ Rather, a double-blind trial by Galasko et al noted that cognitive decline appeared accelerated in AD subjects given a combination of antioxidants, in spite of diminished oxidative stress markers. ${ }^{123}$ As with other vitamins, these inconsistencies may arise from the form of antioxidant under consideration, where supplements, as opposed to dietary antioxidants, may prove less effective; though further study is required to ascertain the validity of this supposition.

The most controversial debate in the realm of antioxidants has been relating to the minerals zinc and copper. With some variability, serum zinc deficiency has been repeatedly correlated with AD. ${ }^{124-127}$ The zinc cation $\left(\mathrm{Zn}^{2+}\right)$ is integral to neural enzymes mediating clearance of $\mathrm{A} \beta$, APP processing and the neutralization of reactive oxidative species, all of which imply a protective role for zinc in $\mathrm{AD} .{ }^{125,128}$ However, $\mathrm{Zn}^{2+}$ is often elevated in $\mathrm{AD}$ brains and has also been directly implicated in potentiating the neurotoxicity of $\mathrm{A} \beta$ and tau; further, by binding to $\mathrm{A} \beta, \mathrm{Zn}^{2+}$ may promote oligomerization. ${ }^{128-130}$ This inconsistency has brought the role of $\mathrm{Zn}^{2+}$ into dispute, and studies have speculated on a potential dual role in the context of AD. ${ }^{131}$

However, it is more likely that $\mathrm{Zn}^{2+}$ levels are elevated in the brain as a physiological countermeasure against the oxidative and inflammatory stress of AD. This would decrease serum $\mathrm{Zn}^{2+}$ concentrations, as observed, but may elevate cerebral $\mathrm{Zn}^{2+}$ to toxic levels, perpetuating the observed pathological functions. This phenomenon, termed zinc flooding, implies that dietary zinc should be reduced, in spite of the observed zinc deficiency among Alzheimer's patients. The copper ion $\left(\mathrm{Cu}^{2+}\right)$ has similarly been implicated in $\mathrm{AD}$, sharing much the same associations as $\mathrm{Zn}^{2+}$. Studies have shown that binding of $\mathrm{Cu}^{2+}$ to $\mathrm{A} \beta$ may lead to the creation of neurotoxic products and that it may have further roles in mediating the characteristic oxidative signature of $\mathrm{AD} .^{132-134}$ However, as with zinc, $\mathrm{Cu}^{2+}$ deficiencies have also been linked to AD. ${ }^{135}$ As reported by Quinn et al, these contradictions have led to the investigation of both copper-sequestering and coppersupplementing agents in clinical trials. ${ }^{136}$

In general, inconsistencies are ubiquitous when considering the role of individual micronutrients in AD. It is likely that variations in dosing, disease stage and the form of nutrient may influence any perceived utility on AD risk or progression. Furthermore, few studies have attempted to consider any broad synergistic effects among differing nutrients, preferring instead to focus on a single cause-and-effect relationship. As diets seldom provide nutrients in isolation, traditional trials may fail to capture the inherent interactions among different dietary elements.

\section{Dietary Patterns}

Analysis of larger dietary patterns may alleviate some of the uncertainties raised by single-nutrient trials. In particular, they offer the ability to examine the role of nutrients in situ or as components of a larger system rather than distinct entities. Among the best studied has been the Mediterranean diet (MeDi). In studies of other diseases, the MeDi has demonstrated significant reductions in mortality and morbidity. ${ }^{137,138}$ The MeDi may have benefit in $\mathrm{AD}$ as it features many nutrients suggested to have beneficial impacts on AD risk and progression. This includes a high intake of fruits and vegetables, rich in natural antioxidants and $\omega-3$ unsaturated fatty acids (in the form of fresh fish and olive oil). Moreover, the diet is low in saturated fats, cholesterol, highfat dairy products and red meats. ${ }^{139}$ It therefore excludes many of the known foods associated with AD risk, and includes several protective nutrients. ${ }^{140}$ It is thus unsurprising that in numerous studies and meta-analyses, adherence to the MeDi was correlated with a reduced risk of AD. ${ }^{141-143}$ Scarmeas et al were further able to demonstrate that in addition to $\mathrm{AD}$ onset, the MeDi also reduced the risk of mortality after diagnosis. ${ }^{144}$

Other diets, such as the "Dietary Approaches to Stop Hypertension" (DASH) diet were associated with improved cognition in hypertensive cohorts. ${ }^{145}$ Observational studies have also correlated general diet quality to cognition in non-demented cohorts. ${ }^{146,147}$ It is noteworthy that when attempting to resolve this effect, no single element of the diet could be independently associated with the purported benefits. Even supplementation of multiple discrete nutrients have proved clinically insignificant, as was the case in a recent trail of Souvenaid (branded Fortasyn Connect) which provided a preformulated combination $\omega-3$ PUFAs, synaptic 
membrane precursors, cofactors and vitamins. ${ }^{148,149}$ Therefore, it is likely that a complex additive relationship may sustain the observed benefits of the MeDi and other diets.

\section{Perspectives on the Microbiota}

Although the human microbiota has recently emerged as a major contributor to various disease states, it remained largely unexplored in the field of neurology until the recognition of the gut-brain axis, which revealed the existence of complex bilateral communication between the brain and the intestines. ${ }^{150}$ To date, investigations have catalogued a variety of signaling molecules originating from the gut as modulators of pain, stress and possibly emotions. $^{151-153}$ Murine models have also demonstrated significant behavioral and biochemical differences in animals raised with a sterile gut, which can be restored after colonization with probiotic bacteria. 154

The role of microbiota in $\mathrm{AD}$ is an emerging area of study. From preliminary data, we glean three gross mechanisms by which the microbiota may influence AD. The first involves the well-studied ability of the microbiota to affect nutrient absorption and activation. ${ }^{155}$ Jandhyala et al report that absorption and activation of polyphenols, a class of organic antioxidants with protective associations in $\mathrm{AD}$, is contingent on enteric microbial enzymes. ${ }^{156}$ Likewise, the absorption of $\omega-3$ fatty acids ${ }^{157}$ and the bioavailability of macronutrients may also depend on the state and composition of the microbiome. ${ }^{158}$ It is therefore conceivable that the microbiota may mediate the physiological levels of the nutrients implicated in AD. Thus, the microbiota may cause identical quantities of administered nutrients to result in substantially different concentrations within the body. The failure of most trials to account for this may therefore offer some explanation for the inability of nutrient-based trials to demonstrate associations on AD. However, this remains speculative pending definitive quantification of the potential influence and variability imposed by the microbiota.

A second emerging mechanism lies in the capacity of the microbiota to modulate inflammation. The gut is known to be a source for various oxidative stressors and signals, ${ }^{159,160}$ and recent data by Bruce-Keller et al and others have demonstrated that varying the microbiota can directly alter inflammation, both in the brain and systemically. ${ }^{161,162}$ Studies have narrowed this tendency to specific bacterial species, which can secrete or otherwise generate pro-inflammatory cytokines; others may counteract this signaling by producing anti-inflammatory agents. ${ }^{159,160,162}$ Notably, it was microbes thriving in a high-fat environment that were directly associated with elevated neuroinflammation. ${ }^{161}$ Mice enriched with these bacteria further demonstrated significant behavioral changes in several domains, in comparison to healthy controls. ${ }^{161}$ As high fat consumption and inflammation are directly associated with $\mathrm{AD}$, it is conceivable that the microbiota may, at least in part, moderate the pathogenic effects of fats in AD.

Data have also suggested a role for the microbiota in amyloidogenesis. Bacteria may perpetuate the leakage of dietary amyloids into the blood, where they may eventually enter the nervous system and seed further amyloid transformations. ${ }^{163,164}$ The gut may therefore facilitate $\mathrm{A} \beta$ oligomerization in a manner similar to transmissible encephalopathies or prion diseases. ${ }^{163}$ However, this theory is again speculative and has yet to be proven in patients. It is also unlikely any pathogenic amyloids derived from diet may preserve their unique misfolded conformations as they pass through the gastrointestinal tract. Nonetheless, it is now known that in transgenic murine models $(3 \mathrm{xTg})$ of $\mathrm{AD}$, a probiotic formula can slow cognitive decline and decrease amyloid plaques in the brain. ${ }^{165} \mathrm{~A}$ role for the microbiota in AD is therefore possible. In future, this should be a field of study, and trials, particularly in nutrition should begin to consider the state of the microbiota as a potential disrupting variable.

\section{Alzheimer's Disease, Drugs ANd Diet}

We have thus far summarized how diet may mediate the onset and progression of $\mathrm{AD}$. Although this has been the principal focus of nutritional studies, the reciprocal relationship, wherein AD may alter diet, is also an emerging area of investigation. As early as 1990, Mungas et al demonstrated that patients with dementia displayed significantly altered dietary preferences when compared with healthy controls. ${ }^{166}$ Specifically, they preferred high-fat and/ or high-sugar foods, which may arise from diminished inhibition of cravings. ${ }^{166}$ More recent data suggest that various forms of dementia are associated with broader changes in appetite, food preference, eating habits and swallowing, with up to $80 \%$ of $\mathrm{AD}$ patients displaying some dietary disturbance (although data have varied heavily by form and stage of dementia considered). ${ }^{167-170}$ These conclusions posit an intriguing scenario: AD may drive patients toward a diet that may worsen outcomes and prognoses. The fact that sizable fractions of $\mathrm{AD}$ cohorts are routinely observed with hyperphagia, ${ }^{171-175}$ and poorer adherence to beneficial diets, ${ }^{176}$ add suggestive evidence to this hypothesis.

An alternate scenario suggests that $\mathrm{AD}$ and dementia, particularly in its latter stages, may be associated with malnutrition and nutrient deficiencies. ${ }^{177,178}$ Both are near endemic among elderly and $\mathrm{AD}$ populations, and are well associated with deleterious outcomes and prognosis. ${ }^{179,180}$ It is currently unclear whether AD may be more strongly associated with malnourishment or higher fat and sugar consumption, or a complex mix of both. However, given that both dietary states are known to impact $\mathrm{AD}$, either case implies that $\mathrm{AD}$ and diet may exert a self-modifying interaction, wherein each may modulate the other.

The impact of these associations may also be significant in the context of drug metabolism. Nutrition has long shared associations to the efficacy and bioactivity of drugs, and it is well known that diet is an important determinant of drug metabolism. ${ }^{181}$ A review by Walter-Sack and Klotz summarized many known interactions, including changes in excretion, enzyme function and clearance that have been demonstrated by alterations in diet. ${ }^{181}$ In the context of $\mathrm{AD}$, perhaps the most relevant observation is that a high-fat diet may moderate the clearance of drugs. ${ }^{181-183}$ Studies have also indicated that malnutrition may decrease drug efficacy by impeding requisite biotransformation and activation reactions. ${ }^{184,185}$ States of elevated inflammation may similarly hamper crucial drug activation and metabolism systems. ${ }^{186,187}$ As evidenced previously, inflammation as well as both high-fat diets and malnutrition are endemic in $\mathrm{AD}$, and may be partly perpetuated by AD itself. Though the reported associations have been largely from isolated studies for unrelated disease and drug models-donepezil, rivastigmine and memantine-three major drugs used to manage AD symptoms, are all associated with gastrointestinal reactions and/or appetite 
changes. ${ }^{188-190}$ As such, drugs and diet may conceivably interact in yet another multifaceted, reciprocal interaction, where drugs can modify diet and diet can in turn modify the efficacy of drugs. Although it is premature to know whether this interaction may have any role in $\mathrm{AD}$, these relationships underlie a definitive web of dynamic interactions between diet, drugs and disease (Figure 1).

\section{Diet in Alzheimer's Clinical Trials}

An ideal clinical trial would administer a singular intervention, in isolation, and discern the effect on a discrete therapeutic outcome. However, the complexity of AD inevitably means that numerous interceding factors may modulate outcome measures, irrespective of the action of a potential therapy. In cataloguing the interaction of diet and $\mathrm{AD}$, this review has identified various dietary elements as potential intervening factors (Table 1).
To the best of authors' knowledge, the role of diet has not been systematically considered in the context of a non-nutritional therapeutic agent in AD. Although an array of extensive interactions has now been established, along with a potentially reciprocal self-modifying interactions, studies have largely relied on the control group to mitigate any variability induced by diet. Yet, in raising the variability of cohorts, studies can compromise statistical power, and hinder the observance of the efficacy of a therapy. We therefore suggest that trials in AD proactively consider strategies to account for diet in their study design and analysis.

Shim et al have reviewed approaches to assess diet in the context of epidemiology. ${ }^{191}$ They note that diet may be tracked by objective observation or subjective reports; ${ }^{191}$ however, in AD both may prove challenging. Alzheimer's disease trials require extended follow-up to observe the manifestation of symptoms; thus consistent observations of diet by study personnel is impractical —although it should be considered the gold standard. Likewise, patients with advancing dementia cannot reliably be

Table 1: Summary of mechanistic interactions between major nutrients and AD pathologies

\begin{tabular}{|c|c|c|}
\hline Dietary elements & AD interaction & Reference \\
\hline \multirow[t]{5}{*}{ Cholesterol } & Facilitate $\mathrm{A} \beta$ misfolding & \multirow{5}{*}{$\begin{array}{l}\text { Kakio et al }(2001)^{35} ; \text { Di Scala et al }(2014)^{34} ; \text { Xiong et al }(2008)^{31} ; \\
\text { Thirumangalakudi et al }(2008)^{32} ; \text { Julien et al }(2010)^{48} ; \\
\text { Reviewed by: Liu \& Zhang }(2014)^{33}\end{array}$} \\
\hline & Facilitate $\mathrm{A} \beta$ neurotoxicity & \\
\hline & Increase $\mathrm{A} \beta$ production & \\
\hline & Alter tau dynamics & \\
\hline & Elevated inflammatory/oxidative stress & \\
\hline \multirow[t]{5}{*}{ Saturated fats, trans-fats } & Altered gene expression & \multirow{5}{*}{$\begin{array}{l}\text { Reviewed by: Liu and Zhang }(2014)^{33} \text {; Takechi et al }(2010)^{49} ; \\
\text { Pugazhenthi et al }(2017)^{50} ; \text { Freeman et al }(2014)^{45} ; \text { Nakamura } \\
\text { et al }(2004)^{46} ; \text { Julien et al }(2010)^{48}\end{array}$} \\
\hline & Elevated inflammatory signaling & \\
\hline & Raise oxidative stress & \\
\hline & Predispose to detrimental vascular disorders & \\
\hline & Promote $\mathrm{A} \beta$ and tau pathologies & \\
\hline$\omega-3$ PUFAs & $\begin{array}{l}\text { Favorably regulate inflammation, apoptosis, plasticity (and } \\
\text { others) }\end{array}$ & Summarized by Cole et al $(2009)^{53}$ \\
\hline \multirow[t]{2}{*}{$\omega-6$ PUFAs } & Elevate inflammation & \multirow[t]{2}{*}{ Otsuka et al $(2002)^{66} ;$ Amtul et al $(2012)^{68}$} \\
\hline & Modulate $\mathrm{A} \beta$ dynamics & \\
\hline \multirow[t]{3}{*}{ Sugars } & Inflammatory stress mediation by glucose/insulin dysregulation & \multirow{3}{*}{$\begin{array}{l}\text { Mushtaq et al }(2015)^{75} ; \text { Hong et al }(1997)^{88} \text {; Planel et al }(2007)^{90} \\
\text { Vekrellis et al }(2000)^{91} \text {; Qiu et al }(1998)^{92}\end{array}$} \\
\hline & Promote tau phosphorylation and tangling via insulin signaling & \\
\hline & Promote $\mathrm{A} \beta$ synthesis and degradation via insulin signaling & \\
\hline \multirow[t]{2}{*}{ Vitamin $\mathrm{B}_{1}$ (thiamine) } & Diminish neuronal stress and apoptosis & \multirow{2}{*}{$\begin{array}{l}\text { Wang et al }(2007)^{103} ; \text { Zhang et al }(2011)^{101} ; \text { Karuppagounder et al } \\
\quad(2009)^{104}\end{array}$} \\
\hline & Favorably mediate $\mathrm{A} \beta$ production & \\
\hline \multirow{3}{*}{$\begin{array}{l}\text { Homocysteine and Vitamins } \\
\mathrm{B}_{6}, \mathrm{~B}_{9}, \mathrm{~B}_{12}\end{array}$} & Mediate neurotoxicity & \multirow[t]{3}{*}{ Obeid et al $(2006)^{106} ; \mathrm{Li}$ et al $(2014)^{110} ; \mathrm{Li}$ et al $(2015)^{109}$} \\
\hline & Alter amyloid accumulation (angiopathy) & \\
\hline & Moderate tau pathology & \\
\hline Vitamin $\mathrm{B}_{2}, \mathrm{~B}_{3}$ & Diminish protein pathologies & Green $(2008)^{115}$ \\
\hline Antioxidants & Diminish oxidative stress and neuroinflammation & $\begin{array}{l}\text { Zandi et al (2004) }{ }^{121} \text {; Reviewed by Verdile et al }(2015)^{119} \text {; } \\
\text { Polidori et al }(2014)^{122}\end{array}$ \\
\hline \multirow[t]{4}{*}{ Zinc and Copper } & Mediate $\mathrm{A} \beta$ processing and toxicity & \multirow{4}{*}{$\begin{array}{l}\text { Miller et al }(2010)^{129} ; \text { Huang et al }(2014)^{130} ; \text { Syme et al }(2004)^{134} \\
\text { Reviewed by Nuttall et al }(2014)^{125} ; \text { Watt et al }(2010)^{128} \\
\text { Mathys et al }(2017)^{132}\end{array}$} \\
\hline & Mediate oxidative stress & \\
\hline & Promote $\mathrm{A} \beta$ oligomerization & \\
\hline & Mediate neurotoxicity of protein pathologies & \\
\hline
\end{tabular}

$\mathrm{AD}=$ Alzheimer's disease PUFAs $=$ polyunsaturated fatty acids. 


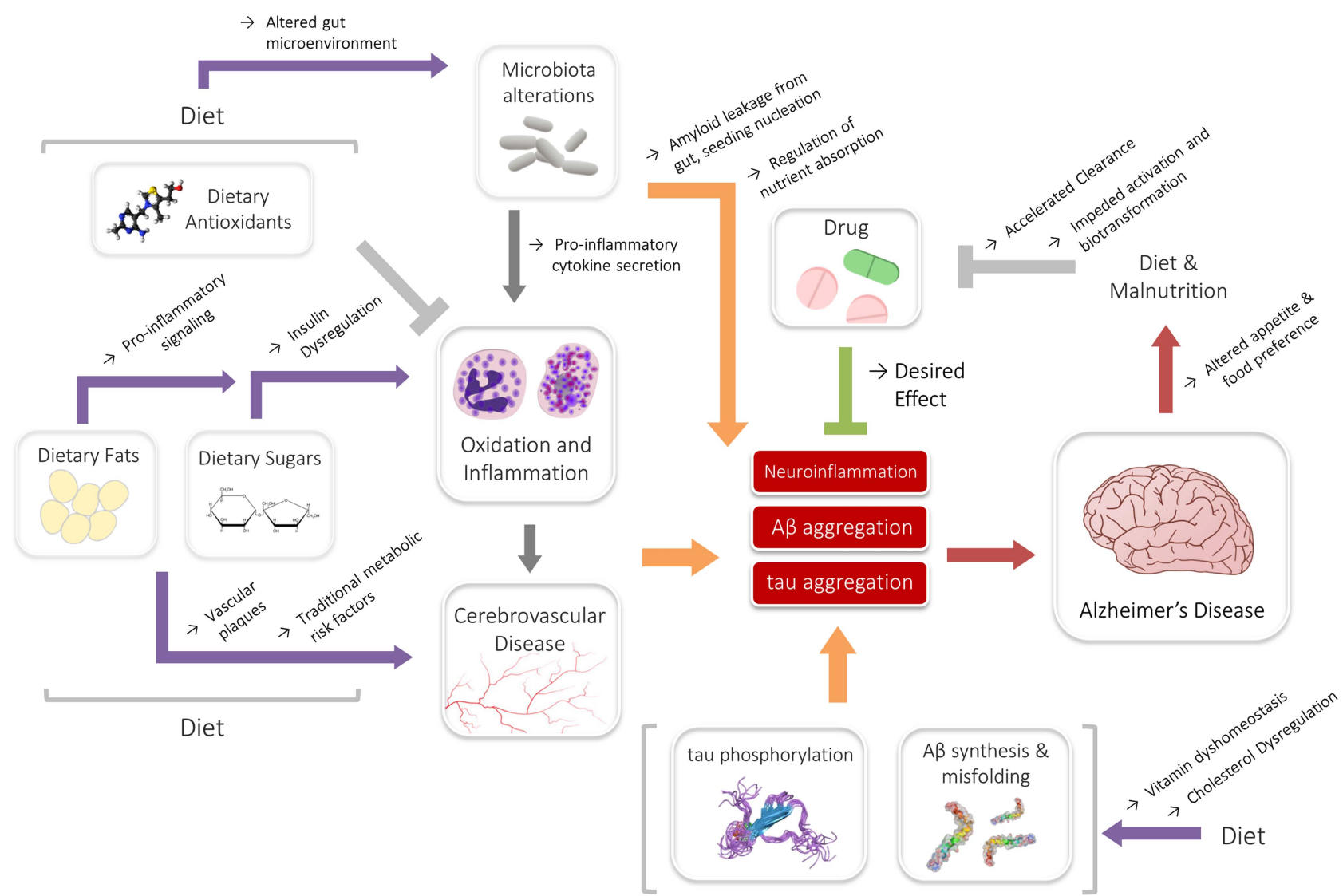

Figure 1: Summary of the interactions of diet, drugs and Alzheimer's disease (AD). Dietary nutrients (fats or sugars) may medicate inflammatory signaling, or contribute toward underlying metabolic states associated with AD. This interaction may be modified by the actions of the microbiota. Likewise, cholesterol and vitamins may interact directly with A $\beta$, contributing to AD risk. Antioxidants and drugs may counteract some of the exacerbating signaling, even though further reciprocal interactions among diet and nutritional status may affect their efficacy.

asked to track food intake or adhere to a prescribed diet. Caregivers may be a potential substitute for self-reporting, yet typical concerns about recall, bias and overburdening may be raised.

A more feasible strategy may be to track baseline dietary preferences in domains like fat, sugar, vitamin and mineral status. In secondary or sensitivity analyses, this data could stratify patients in the exposure and control cohorts into subgroups of comparable diet. Similar results could be attained by multivariate modeling for studies of sufficient size, and appropriate design. Alternatively, for pair-matched control trials, diet may be a factor of consideration when matching subjects and controls. Either strategy may strain study resources, and stratification is known to diminish statistical power. However, these measures may be performed as sensitivity analyses, and accompany primary data, rather than detract from it.

Studies should further consider substantial changes in these nutrients' levels during the study period as a potential confounding interaction. For example, a dramatic rise of cholesterol, an ostensible $\mathrm{A} \beta$ pro-aggregate, or perturbations in micronutrients (including the use of nutritional supplements) may combat the efficacy of an anti-aggregative agent. Likewise, intra-study variations of $\omega-6$ fatty acid levels, or the development of glucose/ insulin dysregulation may alter neuroinflammation, thereby confounding anti-inflammatory therapies. Data on these parameters may serve to refine participant inclusion and exclusion criteria, or shape data analysis and the selection of control subjects as outlined previously.

\section{Conclusions}

A comprehensive analysis of the repeated failure of AD clinical trials must consider secondary factors which may diminish the apparent efficacy of these drugs. Since diet may be a major factor in regulating the onset and progression of $\mathrm{AD}$, as well as influencing the ultimate bioavailability of drugs, we suggest that diet may be an important uncontrolled variable in conventional $\mathrm{AD}$ clinical trial design.

The role of diet in altering AD risk is well established. Nutrients including fats, sugars, minerals and vitamins have been conclusively associated with varying $\mathrm{AD}$ risk and disease progression via a range of mechanisms. Larger dietary patterns have also been definitively linked to $\mathrm{AD}$ risk, and the microbiota is emerging as a potent variable in this context. A reciprocal association in which $\mathrm{AD}$ modulates diet is also conceivable. Notably, the diets that $\mathrm{AD}$ predisposes are those linked with worse prognoses, and impeded drug metabolism. As such, a highly complex set of interactions between diet, $\mathrm{AD}$, and drugs is evident.

This review cannot claim that the failure of experimental drugs in $\mathrm{AD}$ is attributable to diet; however, it does suggest that diet may 
play a role in the outcomes of $\mathrm{AD}$, and the perceived clinical efficacy of novel agents. We therefore suggest that future studies, particularly clinical trials make a concerted effort to monitor, regulate or account for diet among $\mathrm{AD}$ patients. This may require significant investment of resources, and may burden patients and caregivers. Studies may also diminish statistical power depending on the mode of analysis undertaken. However, the extent of diet's interactions with $\mathrm{AD}$ and its apparent role modulating outcomes justifies greater scrutiny in clinical trials.

\section{ACKNOWLEDGEMENTS}

DFW acknowledges salary support from a Tier 1 Canada Research Chair.

\section{Disclosures}

The authors have no relevant financial disclosures.

\section{Statement of Authorship}

All authors contributed equally to the conception, design and drafting of this work.

\section{REFERENCES}

1. Wong SL, Gilmour H, Ramage-Morin PL. Alzheimer's disease and other dementias in Canada. Health Rep. 2016;27(5):11-6.

2. Alzheimer's Association. Alzheimer's disease facts and figures. Alzheimers Dement. 2016;12(4):459-509.

3. Qiu C, Kivipelto M, von Strauss E. Epidemiology of Alzheimer's disease: occurrence, determinants, and strategies toward intervention. Dialogues Clin Neurosci. 2009;11(2):111-28.

4. Cummings JL, Morstorf T, Zhong K. Alzheimer's disease drugdevelopment pipeline: few candidates, frequent failures. Alzheimers Res Ther. 2014;6(4):37.

5. Becker RE, Greig NH, Giacobini E. Why do so many drugs for Alzheimer's disease fail in development? Time for new methods and new practices? J Alzheimers Dis. 2008;15(2):303-25.

6. White L, Petrovitch H, Ross GW, Masaki KH, Abbott RD, Teng EL, et al. Prevalence of dementia in older Japanese-American men in Hawaii: The Honolulu-Asia aging study. JAMA. 1996;276 (12):955-60.

7. Hendrie HC, Ogunniyi A, Hall KS, et al. Incidence of dementia and Alzheimer disease in 2 communities: Yoruba residing in Ibadan, Nigeria, and African Americans residing in Indianapolis, Indiana. JAMA. 2001;285(6):739-47.

8. Reitz C, Mayeux R. Genetics of Alzheimer's disease in Caribbean Hispanic and African American populations. Biol Psychiatry. 2014;75(7):534-41.

9. Tang MX, Cross P, Andrews H, et al. Incidence of AD in AfricanAmericans, Caribbean Hispanics, and Caucasians in northern Manhattan. Neurology. 2001;56(1):49-56.

10. Grant WB. Using multicountry ecological and observational studies to determine dietary risk factors for Alzheimer's disease. J Am Coll Nutr. 2016;35(5):476-89.

11. Tanaka H, Shimabukuro T, Shimabukuro M. High prevalence of metabolic syndrome among men in Okinawa. J Atheroscler Thromb. 2005;12(5):284-8.

12. Grant WB. Trends in diet and Alzheimer's disease during the nutrition transition in Japan and developing countries. J Alzheimers Dis. 2014;38(3):611-20.

13. Perl DP. Neuropathology of Alzheimer's disease. Mt Sinai J Med. 2010;77(1):32-42.

14. Nelson PT, Braak H, Markesbery WR. Neuropathology and cognitive impairment in Alzheimer disease: a complex but coherent relationship. J Neuropathol Exp Neurol. 2009;68(1):1-14.

15. Farlow MR. Etiology and pathogenesis of Alzheimer's disease. Am J Health Syst Pharm. 1998;55(Suppl 2):S5-10.

16. Swerdlow RH. Pathogenesis of Alzheimer's disease. Clin Interv Aging. 2007;2(3):347-59.
17. van der Kant R, Goldstein LS. Cellular functions of the amyloid precursor protein from development to dementia. Dev Cell. 2015;32(4):502-15.

18. Murphy MP, LeVine H, 3rd. Alzheimer's disease and the amyloidbeta peptide. J Alzheimers Dis. 2010;19(1):311-23.

19. Akiyama H, Barger S, Barnum S, et al. Inflammation and Alzheimer's disease. Neurobiol Aging. 2000;21(3):383-421.

20. Iqbal K, Liu F, Gong CX, Grundke-Iqbal I. Tau in Alzheimer disease and related tauopathies. Curr Alzheimer Res. 2010;7 (8):656-64

21. Helzner EP, Scarmeas N, Cosentino S, Tang MX, Schupf N, Stern Y. Survival in Alzheimer disease: a multiethnic, population-based study of incident cases. Neurology. 2008;71(19):1489-95.

22. Wu A, Ying Z, Gomez-Pinilla F. The interplay between oxidative stress and brain-derived neurotrophic factor modulates the outcome of a saturated fat diet on synaptic plasticity and cognition. Eur J Neurosci. 2004;19(7):1699-707.

23. Murphy T, Dias GP, Thuret S. Effects of diet on brain plasticity in animal and human studies: mind the gap. Neural Plast. 2014;2014:563160.

24. Gomez-Pinilla F. Brain foods: the effects of nutrients on brain function. Nat Rev Neurosci. 2008;9(7):568-78.

25. Folch J, Ettcheto M, Petrov D, et al. Review of the advances in treatment for Alzheimer disease: strategies for combating betaamyloid protein. Neurologia. 2018;33(1):47-58.

26. Bronzuoli MR, Iacomino A, Steardo L, Scuderi C. Targeting neuroinflammation in Alzheimer's disease. J Inflamm Res. 2016;9:199-208.

27. DeCarolis NA, Eisch AJ. Hippocampal neurogenesis as a target for the treatment of mental illness: a critical evaluation. Neuropharmacology. 2010;58(6):884-93.

28. Vina J, Lloret A, Orti R, Alonso D. Molecular bases of the treatment of Alzheimer's disease with antioxidants: prevention of oxidative stress. Mol Aspects Med. 2004;25(1-2):117-23.

29. Strittmatter WJ, Saunders AM, Schmechel D, et al. Apolipoprotein E: high-avidity binding to beta-amyloid and increased frequency of type 4 allele in late-onset familial Alzheimer disease. Proc Natl Acad Sci U S A. 1993;90(5):1977-81.

30. Strittmatter WJ, Roses AD. Apolipoprotein E and Alzheimer disease. Proc Natl Acad Sci U S A. 1995;92(11):4725-7.

31. Xiong H, Callaghan D, Jones A, et al. Cholesterol retention in Alzheimer's brain is responsible for high beta- and gamma-secretase activities and Abeta production. Neurobiol Dis. 2008;29(3):422-37.

32. Thirumangalakudi L, Prakasam A, Zhang R, et al. High cholesterolinduced neuroinflammation and amyloid precursor protein processing correlate with loss of working memory in mice. J Neurochem. 2008;106(1):475-85.

33. Liu Q, Zhang J. Lipid metabolism in Alzheimer's disease. Neurosci Bull. 2014;30(2):331-45.

34. Di Scala C, Chahinian H, Yahi N, Garmy N, Fantini J. Interaction of Alzheimer's beta-amyloid peptides with cholesterol: mechanistic insights into amyloid pore formation. Biochemistry. 2014;53 (28):4489-502.

35. Kakio A, Nishimoto SI, Yanagisawa K, Kozutsumi Y, Matsuzaki K. Cholesterol-dependent formation of GM1 ganglioside-bound amyloid beta-protein, an endogenous seed for Alzheimer amyloid. J Biol Chem. 2001;276(27):24985-90.

36. Lin FC, Chuang YS, Hsieh HM, et al. Early statin use and the progression of Alzheimer disease: a total population-based casecontrol study. Medicine (Baltimore). 2015;94(47):e2143.

37. Shepardson NE, Shankar GM, Selkoe DJ. Cholesterol level and statin use in Alzheimer disease: II. Review of human trials and recommendations. Arch Neurol. 2011;68(11):1385-92.

38. Kim Y, Kim C, Jang HY, Mook-Jung I. Inhibition of cholesterol biosynthesis reduces gamma-secretase activity and amyloid-beta generation. J Alzheimers Dis. 2016;51(4):1057-68.

39. Mielke MM, Zandi PP, Shao H, et al. The 32-year relationship between cholesterol and dementia from midlife to late life. Neurology. 2010;75(21):1888-95.

40. Presecki P, Muck-Seler D, Mimica N, et al. Serum lipid levels in patients with Alzheimer's disease. Coll Antropol. 2011;35(Suppl 1):115-20. 
41. Qin Q, Liao G, Baudry M, Bi X. Cholesterol perturbation in mice results in p53 degradation and axonal pathology through p38 MAPK and Mdm2 activation. PLoS One. 2010;5(4):e9999.

42. Mathews ES, Appel B. Cholesterol biosynthesis supports myelin gene expression and axon ensheathment through modulation of $\mathrm{P} 13 \mathrm{~K} / \mathrm{Akt} / \mathrm{mTor}$ signaling. J Neurosci. 2016;36 (29):7628-39.

43. Foot M, Cruz TF, Clandinin MT. Influence of dietary fat on the lipid composition of rat brain synaptosomal and microsomal membranes. Biochem J. 1982;208(3):631-40.

44. Morris MC, Evans DA, Bienias JL, et al. Dietary fats and the risk of incident Alzheimer disease. Arch Neurol. 2003;60 (2):194-200.

45. Freeman LR, Haley-Zitlin V, Rosenberger DS, Granholm AC. Damaging effects of a high-fat diet to the brain and cognition: a review of proposed mechanisms. Nutr Neurosci. 2014;17 (6):241-51

46. Nakamura MT, Cheon Y, Li Y, Nara TY. Mechanisms of regulation of gene expression by fatty acids. Lipids. 2004:39(11):1077-83.

47. Lloyd HM, Green MW, Rogers PJ. Mood and cognitive performance effects of isocaloric lunches differing in fat and carbohydrate content. Physiol Behav. 1994;56(1):51-7.

48. Julien C, Tremblay C, Phivilay A, et al. High-fat diet aggravates amyloid-beta and tau pathologies in the $3 \mathrm{xTg}$-AD mouse model. Neurobiol Aging. 2010;31(9):1516-31

49. Takechi R, Galloway S, Pallebage-Gamarallage MM, Lam V, Mamo JC. Dietary fats, cerebrovasculature integrity and Alzheimer's disease risk. Prog Lipid Res. 2010;49(2):159-70.

50. Pugazhenthi S, Qin L, Reddy PH. Common neurodegenerative pathways in obesity, diabetes, and Alzheimer's disease. Biochim Biophys Acta. 2017;1863(5):1037-45.

51. Engelhart MJ, Geerlings MI, Ruitenberg A, et al. Diet and risk of dementia: does fat matter? The Rotterdam Study. Neurology. 2002;59(12):1915-21.

52. Hooijmans CR, Pasker-de Jong PC, de Vries RB, Ritskes-Hoitinga $\mathrm{M}$. The effects of long-term omega-3 fatty acid supplementation on cognition and Alzheimer's pathology in animal models of Alzheimer's disease: a systematic review and meta-analysis. J Alzheimers Dis. 2012;28(1):191-209.

53. Cole GM, Ma QL, Frautschy SA. Omega- 3 fatty acids and dementia. Prostaglandins Leukot Essent Fatty Acids. 2009;81(2-3):213-21.

54. Yurko-Mauro K. Cognitive and cardiovascular benefits of docosahexaenoic acid in aging and cognitive decline. Curr Alzheimer Res. 2010;7(3):190-6.

55. Morris MC, Evans DA, Bienias JL, et al. Consumption of fish and n-3 fatty acids and risk of incident Alzheimer disease. Arch Neurol. 2003;60(7):940-6.

56. Gu Y, Schupf N, Cosentino SA, Luchsinger JA, Scarmeas N. Nutrient intake and plasma beta-amyloid. Neurology. 2012;78 (23): $1832-40$

57. Olivera-Perez HM, Lam L, Dang J, et al. Omega-3 fatty acids increase the unfolded protein response and improve amyloid-beta phagocytosis by macrophages of patients with mild cognitive impairment. FASEB J. 2017;31(10):4359-69.

58. Siegel G, Ermilov E. Omega-3 fatty acids: benefits for cardiocerebro-vascular diseases. Atherosclerosis. 2012;225(2):291-5

59. Freund-Levi Y, Hjorth E, Lindberg C, et al. Effects of omega-3 fatty acids on inflammatory markers in cerebrospinal fluid and plasma in Alzheimer's disease: the OmegAD study. Dement Geriatr Cogn Disord. 2009;27(5):481-90.

60. Devore EE, Grodstein F, van Rooij FJ, et al. Dietary intake of fish and omega-3 fatty acids in relation to long-term dementia risk. Am J Clin Nutr. 2009;90(1):170-6.

61. Arendash GW, Jensen MT, Salem N Jr., et al. A diet high in omega-3 fatty acids does not improve or protect cognitive performance in Alzheimer's transgenic mice. Neuroscience. 2007;149(2):286302.

62. Barberger-Gateau P, Samieri C, Feart C, Plourde M. Dietary omega 3 polyunsaturated fatty acids and Alzheimer's disease: interaction with apolipoprotein E genotype. Curr Alzheimer Res. 2011;8 (5):479-91.

63. Araya-Quintanilla F, Gutierrez-Espinoza H, Sanchez-Montoya U, et al. Effectiveness of omega-3 fatty acid supplementation in patients with Alzheimer disease: A systematic review and metaanalysis. Neurologia. 2017.

64. Mazereeuw G, Lanctot KL, Chau SA, Swardfager W, Herrmann N. Effects of omega-3 fatty acids on cognitive performance: a metaanalysis. Neurobiol Aging. 2012;33(7):1482 e17-29.

65. Creegan R, Hunt W, McManus A, Rainey-Smith SR. Diet, nutrients and metabolism: cogs in the wheel driving Alzheimer's disease pathology? Br J Nutr. 2015;113(10):1499-517.

66. Otsuka M, Yamaguchi K, Ueki A. Similarities and differences between Alzheimer's disease and vascular dementia from the viewpoint of nutrition. Ann N Y Acad Sci. 2002;977:155-61.

67. Baierle M, Vencato PH, Oldenburg L, et al. Fatty acid status and its relationship to cognitive decline and homocysteine levels in the elderly. Nutrients. 2014;6(9):3624-40.

68. Amtul Z, Uhrig M, Wang L, Rozmahel RF, Beyreuther K. Detrimental effects of arachidonic acid and its metabolites in cellular and mouse models of Alzheimer's disease: structural insight. Neurobiol Aging. 2012;33(4):831 e21-31.

69. Hosono T, Nishitsuji K, Nakamura T, et al. Arachidonic acid diet attenuates brain Abeta deposition in $\mathrm{Tg} 2576$ mice. Brain Res. 2015;1613:92-9.

70. Tokuda H, Kontani M, Kawashima H, Kiso Y, Shibata H, Osumi N. Differential effect of arachidonic acid and docosahexaenoic acid on age-related decreases in hippocampal neurogenesis. Neurosci Res. 2014;88:58-66.

71. Otsuka M. [Prevention of Alzheimer's Disease and Nutrients]. Brain Nerve. 2016;68(7):809-17.

72. Gustaw-Rothenberg K. Dietary patterns associated with Alzheimer's disease: population based study. Int J Environ Res Public Health. 2009;6(4):1335-40.

73. Crane PK, Walker R, Hubbard RA, et al. Glucose levels and risk of dementia. N Engl J Med. 2013;369(6):540-8.

74. Luchsinger JA, Tang MX, Shea S, Mayeux R. Caloric intake and the risk of Alzheimer disease. Arch Neurol. 2002;59(8):1258-63.

75. Mushtaq G, Khan JA, Kumosani TA, Kamal MA. Alzheimer's disease and type 2 diabetes via chronic inflammatory mechanisms. Saudi J Biol Sci. 2015;22(1):4-13.

76. Moreira PI. High-sugar diets, type 2 diabetes and Alzheimer's disease. Curr Opin Clin Nutr Metab Care. 2013;16(4):440-5.

77. Akter K, Lanza EA, Martin SA, Myronyuk N, Rua M, Raffa RB. Diabetes mellitus and Alzheimer's disease: shared pathology and treatment? Br J Clin Pharmacol. 2011;71(3):365-76.

78. Peila R, Rodriguez BL, Launer LJ, Honolulu-Asia Aging S. Type 2 diabetes, APOE gene, and the risk for dementia and related pathologies: The Honolulu-Asia Aging Study. Diabetes. 2002;51 (4):1256-62.

79. Ishii K, Sasaki M, Kitagaki H, et al. Reduction of cerebellar glucose metabolism in advanced Alzheimer's disease. J Nucl Med. 1997;38(6):925-8.

80. Iadecola C. Sugar and Alzheimer's disease: a bittersweet truth. Nat Neurosci. 2015;18(4):477-8.

81. Hoyer S, Oesterreich K, Wagner O. Glucose metabolism as the site of the primary abnormality in early-onset dementia of Alzheimer type? J Neurol. 1988;235(3):143-8.

82. Wattamwar PR, Mathuranath PS. An overview of biomarkers in Alzheimer's disease. Ann Indian Acad Neurol. 2010;13(Suppl 2): S116-23.

83. Szablewski L. Glucose transporters in brain: in health and in Alzheimer's disease. J Alzheimers Dis. 2017;55(4):1307-20.

84. Winkler EA, Nishida Y, Sagare AP, et al. GLUT1 reductions exacerbate Alzheimer's disease vasculo-neuronal dysfunction and degeneration. Nat Neurosci. 2015;18(4):521-30.

85. McNay EC, Recknagel AK. Brain insulin signaling: a key component of cognitive processes and a potential basis for cognitive impairment in type 2 diabetes. Neurobiol Learn Mem. 2011;96 (3):432-42.

86. Chiu SL, Cline HT. Insulin receptor signaling in the development of neuronal structure and function. Neural Dev. 2010;5:7.

87. Akintola AA, van Heemst D. Insulin, aging, and the brain: mechanisms and implications. Front Endocrinol (Lausanne). 2015;6:13.

88. Hong M, Lee VM. Insulin and insulin-like growth factor-1 regulate tau phosphorylation in cultured human neurons. J Biol Chem. 1997;272(31):19547-53 
89. El Khoury NB, Gratuze M, Papon MA, Bretteville A, Planel E. Insulin dysfunction and Tau pathology. Front Cell Neurosci. 2014;8:22.

90. Planel E, Tatebayashi Y, Miyasaka T, et al. Insulin dysfunction induces in vivo tau hyperphosphorylation through distinct mechanisms. J Neurosci. 2007;27(50):13635-48.

91. Vekrellis K, Ye Z, Qiu WQ, et al. Neurons regulate extracellular levels of amyloid beta-protein via proteolysis by insulindegrading enzyme. J Neurosci. 2000;20(5):1657-65.

92. Qiu WQ, Walsh DM, Ye Z, et al. Insulin-degrading enzyme regulates extracellular levels of amyloid beta-protein by degradation. J Biol Chem. 1998;273(49):32730-8.

93. Craft S. Insulin resistance and Alzheimer's disease pathogenesis: potential mechanisms and implications for treatment. Curr Alzheimer Res. 2007:4(2):147-52.

94. Mosconi L, Pupi A, De Leon MJ. Brain glucose hypometabolism and oxidative stress in preclinical Alzheimer's disease. Ann N Y Acad Sci. 2008;1147:180-95.

95. Luchsinger JA, Noble JM, Scarmeas N. Diet and Alzheimer's disease. Curr Neurol Neurosci Rep. 2007;7(5):366-72.

96. Huskisson E, Maggini S, Ruf M. The role of vitamins and minerals in energy metabolism and well-being. J Int Med Res. 2007;35 (3):277-89.

97. Butterworth RF. Effects of thiamine deficiency on brain metabolism: implications for the pathogenesis of the Wernicke-Korsakoff syndrome. Alcohol Alcohol. 1989;24(4):271-9.

98. Rodríguez J-L, Qizilbash N, López-Arrieta J, Rodríguez J-L. Thiamine for Alzheimer's disease. Cochrane Database of Systematic Reviews. 2001.

99. Gibson GE, Hirsch JA, Cirio RT, Jordan BD, Fonzetti P, Elder J. Abnormal thiamine-dependent processes in Alzheimer's disease. Lessons from diabetes. Mol Cell Neurosci. 2013;55:1725.

100. Gold M, Hauser RA, Chen MF. Plasma thiamine deficiency associated with Alzheimer's disease but not Parkinson's disease. Metab Brain Dis. 1998;13(1):43-53.

101. Zhang Q, Yang G, Li W, et al. Thiamine deficiency increases betasecretase activity and accumulation of beta-amyloid peptides. Neurobiol Aging. 2011;32(1):42-53.

102. Ba A. Metabolic and structural role of thiamine in nervous tissues. Cell Mol Neurobiol. 2008;28(7):923-31

103. Wang X, Wang B, Fan Z, Shi X, Ke ZJ, Luo J. Thiamine deficiency induces endoplasmic reticulum stress in neurons. Neuroscience. 2007;144(3):1045-56.

104. Karuppagounder SS, Xu H, Shi Q, et al. Thiamine deficiency induces oxidative stress and exacerbates the plaque pathology in Alzheimer's mouse model. Neurobiol Aging. 2009;30(10):1587600.

105. Koh F, Charlton KE, Walton K, et al. Protein and thiamin intakes are not related to cognitive function in well-nourished community-living older adults. Nutr Diet. 2015;72(1):47-53.

106. Obeid R, Herrmann W. Mechanisms of homocysteine neurotoxicity in neurodegenerative diseases with special reference to dementia. FEBS Lett. 2006;580(13):2994-3005.

107. Seshadri S, Beiser A, Selhub J, et al. Plasma homocysteine as a risk factor for dementia and Alzheimer's disease. N Engl J Med. 2002;346(7):476-83.

108. Beydoun MA, Beydoun HA, Gamaldo AA, Teel A, Zonderman $\mathrm{AB}$, Wang Y. Epidemiologic studies of modifiable factors associated with cognition and dementia: systematic review and metaanalysis. BMC Public Health. 2014;14:643.

109. Li JG, Pratico D. High levels of homocysteine results in cerebral amyloid angiopathy in mice. J Alzheimers Dis. 2015;43 (1):29-35.

110. Li JG, Chu J, Barrero C, Merali S, Pratico D. Homocysteine exacerbates beta-amyloid pathology, tau pathology, and cognitive deficit in a mouse model of Alzheimer disease with plaques and tangles. Ann Neurol. 2014;75(6):851-63.

111. Wang HX, Wahlin A, Basun H, Fastbom J, Winblad B, Fratiglioni L. Vitamin $\mathrm{B}(12)$ and folate in relation to the development of Alzheimer's disease. Neurology. 2001;56(9):1188-94.

112. Morris MC, Evans DA, Schneider JA, Tangney CC, Bienias JL, Aggarwal NT. Dietary folate and vitamins B-12 and B-6 not associated with incident Alzheimer's disease. J Alzheimers Dis. 2006;9(4):435-43.

113. Doets EL, van Wijngaarden JP, Szczecinska A, et al. Vitamin B12 intake and status and cognitive function in elderly people. Epidemiol Rev. 2013;35:2-21.

114. Nelson C, Wengreen HJ, Munger RG, Corcoran CD. Dietary folate, vitamin B-12, vitamin B-6 and incident Alzheimer's disease: the cache county memory, health and aging study. J Nutr Health Aging. 2009;13(10):899-905.

115. Green KN, Steffan JS, Martinez-Coria H, et al. Nicotinamide restores cognition in Alzheimer's disease transgenic mice via a mechanism involving sirtuin inhibition and selective reduction of Thr231-phosphotau. J Neurosci. 2008;28(45):11500-10.

116. Morris MC, Evans DA, Bienias JL, et al. Dietary niacin and the risk of incident Alzheimer's disease and of cognitive decline. J Neurol Neurosurg Psychiatry. 2004;75(8):1093-9.

117. Phelan MJ. Phase II clinical trial of nicotinamide for the treatment of mild to moderate Alzheimer's disease. J Geriatr Med Gerontol. 2017;3:1.

118. Morris MC. Diet and Alzheimer's disease: what the evidence shows. MedGenMed. 2004;6(1):48.

119. Verdile G, Keane KN, Cruzat VF, et al. Inflammation and oxidative stress: the molecular connectivity between insulin resistance, obesity, and Alzheimer's disease. Mediators Inflamm. 2015;2015:105828.

120. Wyss-Coray T, Rogers J. Inflammation in Alzheimer disease: a brief review of the basic science and clinical literature. Cold Spring Harb Perspect Med. 2012;2(1):a006346.

121. Zandi PP, Anthony JC, Khachaturian AS, et al. Reduced risk of Alzheimer disease in users of antioxidant vitamin supplements: the Cache County Study. Arch Neurol. 2004;61(1):82-8.

122. Polidori MC, Nelles G. Antioxidant clinical trials in mild cognitive impairment and Alzheimer's disease - challenges and perspectives. Curr Pharm Des. 2014;20(18):3083-92.

123. Galasko DR, Peskind E, Clark CM, et al. Antioxidants for Alzheimer disease: a randomized clinical trial with cerebrospinal fluid biomarker measures. Arch Neurol. 2012;69(7):836-41.

124. Tully CL, Snowdon DA, Markesbery WR. Serum zinc, senile plaques, and neurofibrillary tangles: findings from the Nun Study. Neuroreport. 1995;6(16):2105-8.

125. Nuttall JR, Oteiza PI. Zinc and the aging brain. Genes Nutr. 2014;9 (1):379.

126. Brewer GJ, Kaur S. Zinc deficiency and zinc therapy efficacy with reduction of serum free copper in Alzheimer's disease. Int J Alzheimers Dis. 2013;2013:586365.

127. Ventriglia M, Brewer GJ, Simonelli I, et al. Zinc in Alzheimer's disease: a meta-analysis of serum, plasma, and cerebrospinal fluid studies. J Alzheimers Dis. 2015;46(1):75-87.

128. Watt NT, Whitehouse IJ, Hooper NM. The role of zinc in Alzheimer's disease. Int J Alzheimers Dis. 2010;2011:971021.

129. Miller Y, Ma B, Nussinov R. Zinc ions promote Alzheimer Abeta aggregation via population shift of polymorphic states. Proc Natl Acad Sci U S A. 2010;107(21):9490-5.

130. Huang Y, Wu Z, Cao Y, Lang M, Lu B, Zhou B. Zinc binding directly regulates tau toxicity independent of tau hyperphosphorylation. Cell Rep. 2014;8(3):831-42.

131. Huang X, Cuajungco MP, Atwood CS, Moir RD, Tanzi RE, Bush AI. Alzheimer's disease, beta-amyloid protein and zinc. J Nutr. 2000;130(5S Suppl):1488S-492SS.

132. Mathys ZK, White AR. Copper and Alzheimer's disease. Adv Neurobiol. 2017;18:199-216.

133. Squitti R, Siotto M, Polimanti R. Low-copper diet as a preventive strategy for Alzheimer's disease. Neurobiol Aging. 2014;35 (Suppl 2):S40-50.

134. Syme CD, Nadal RC, Rigby SE, Viles JH. Copper binding to the amyloid-beta (Abeta) peptide associated with Alzheimer's disease: folding, coordination geometry, $\mathrm{pH}$ dependence, stoichiometry, and affinity of Abeta-(1-28): insights from a range of complementary spectroscopic techniques. J Biol Chem. 2004;279 (18):18169-77.

135. Xu J, Church SJ, Patassini S, et al. Evidence for widespread, severe brain copper deficiency in Alzheimer's dementia. Metallomics. 2017;9(8):1106-19. 
136. Quinn JF, Crane S, Harris C, Wadsworth TL. Copper in Alzheimer's disease: too much or too little? Expert Rev Neurother. 2009;9(5):631-7.

137. Martinez-Gonzalez MA, Bes-Rastrollo M. Dietary patterns, Mediterranean diet, and cardiovascular disease. Curr Opin Lipidol. 2014;25(1):20-6

138. Grosso G, Mistretta A, Frigiola A, et al. Mediterranean diet and cardiovascular risk factors: a systematic review. Crit Rev Food Sci Nutr. 2014;54(5):593-610.

139. Huhn S, Kharabian Masouleh S, Stumvoll M, Villringer A, Witte AV. Components of a Mediterranean diet and their impact on cognitive functions in aging. Front Aging Neurosci. 2015;7:132.

140. Gu Y, Nieves JW, Stern Y, Luchsinger JA, Scarmeas N. Food combination and Alzheimer disease risk: a protective diet. Arch Neurol. 2010;67(6):699-706.

141. Scarmeas N, Stern Y, Tang MX, Mayeux R, Luchsinger JA. Mediterranean diet and risk for Alzheimer's disease. Ann Neurol. 2006;59(6):912-21.

142. Scarmeas N, Stern Y, Mayeux R, Luchsinger JA. Mediterranean diet, Alzheimer disease, and vascular mediation. Arch Neurol. 2006;63(12):1709-17.

143. Sofi F, Cesari F, Abbate R, Gensini GF, Casini A. Adherence to Mediterranean diet and health status: meta-analysis. BMJ. 2008;337:a1344.

144. Scarmeas N, Luchsinger JA, Mayeux R, Stern Y. Mediterranean diet and Alzheimer disease mortality. Neurology. 2007;69 (11):1084-93.

145. Smith PJ, Blumenthal JA, Babyak MA, et al. Effects of the dietary approaches to stop hypertension diet, exercise, and caloric restriction on neurocognition in overweight adults with high blood pressure. Hypertension. 2010;55(6):1331-8.

146. Correa Leite ML, Nicolosi A, Cristina S, Hauser WA, Nappi G. Nutrition and cognitive deficit in the elderly: a population study. Eur J Clin Nutr. 2001;55(12):1053-8.

147. Wengreen HJ, Neilson C, Munger R, Corcoran C. Diet quality is associated with better cognitive test performance among aging men and women. J Nutr. 2009;139(10):1944-9.

148. Ritchie CW, Bajwa J, Coleman G, et al. Souvenaid(R): a new approach to management of early Alzheimer's disease. J Nutr Health Aging. 2014;18(3):291-9.

149. Soininen H, Solomon A, Visser PJ, et al. 24-month intervention with a specific multinutrient in people with prodromal Alzheimer's disease (LipiDiDiet): a randomised, double-blind, controlled trial. Lancet Neurol. 2017;16(12):965-75.

150. Carabotti M, Scirocco A, Maselli MA, Severi C. The gut-brain axis: interactions between enteric microbiota, central and enteric nervous systems. Ann Gastroenterol. 2015;28(2):203-9.

151. Mayer EA, Tillisch K, Gupta A. Gut/brain axis and the microbiota. J Clin Invest. 2015;125(3):926-38.

152. Foster JA, McVey Neufeld KA. Gut-brain axis: how the microbiome influences anxiety and depression. Trends Neurosci. 2013;36(5):305-12.

153. Cryan JF, Dinan TG. Mind-altering microorganisms: the impact of the gut microbiota on brain and behaviour. Nat Rev Neurosci. 2012;13(10):701-12.

154. Sampson TR, Mazmanian SK. Control of brain development, function, and behavior by the microbiome. Cell Host Microbe. 2015;17(5):565-76.

155. Moco S, Martin FP, Rezzi S. Metabolomics view on gut microbiome modulation by polyphenol-rich foods. J Proteome Res. 2012;11(10):4781-90

156. Jandhyala SM, Talukdar R, Subramanyam C, Vuyyuru H, Sasikala M, Nageshwar Reddy D. Role of the normal gut microbiota. World J Gastroenterol. 2015;21(29):8787-803.

157. Menni C, Zierer J, Pallister T, et al. Omega-3 fatty acids correlate with gut microbiome diversity and production of $\mathrm{N}$-carbamylglutamate in middle aged and elderly women. Sci Rep. 2017;7(1):11079.

158. Krajmalnik-Brown R, Ilhan ZE, Kang DW, DiBaise JK. Effects of gut microbes on nutrient absorption and energy regulation. Nutr Clin Pract. 2012;27(2):201-14.

159. Hakansson A, Molin G. Gut microbiota and inflammation. Nutrients. 2011;3(6):637-82.
160. Boulange CL, Neves AL, Chilloux J, Nicholson JK, Dumas ME. Impact of the gut microbiota on inflammation, obesity, and metabolic disease. Genome Med. 2016;8(1):42.

161. Bruce-Keller AJ, Salbaum JM, Luo M, et al. Obese-type gut microbiota induce neurobehavioral changes in the absence of obesity. Biol Psychiatry. 2015;77(7):607-15.

162. Mu C, Yang Y, Zhu W. Gut microbiota: the brain peacekeeper. Front Microbiol. 2016;7:345.

163. Walker LC, Jucker M. Neurodegenerative diseases: expanding the prion concept. Annu Rev Neurosci. 2015;38:87-103.

164. Pistollato F, Sumalla Cano S, Elio I, Masias Vergara M, Giampieri F, Battino M. Role of gut microbiota and nutrients in amyloid formation and pathogenesis of Alzheimer disease. Nutr Rev. 2016;74(10):624-34

165. Bonfili L, Cecarini V, Berardi S, et al. Microbiota modulation counteracts Alzheimer's disease progression influencing neuronal proteolysis and gut hormones plasma levels. Sci Rep. 2017;7 (1):2426.

166. Mungas D, Cooper JK, Weiler PG, Gietzen D, Franzi C, Bernick C. Dietary preference for sweet foods in patients with dementia. J Am Geriatr Soc. 1990;38(9):999-1007.

167. Ikeda M, Brown J, Holland AJ, Fukuhara R, Hodges JR. Changes in appetite, food preference, and eating habits in frontotemporal dementia and Alzheimer's disease. J Neurol Neurosurg Psychiatry. 2002;73(4):371-6.

168. Kai K, Hashimoto M, Amano K, Tanaka H, Fukuhara R, Ikeda M. Relationship between eating disturbance and dementia severity in patients with Alzheimer's disease. PLoS One. 2015;10(8): e0133666.

169. Fernandez M, Gobartt AL, Balana M, Group CS. Behavioural symptoms in patients with Alzheimer's disease and their association with cognitive impairment. BMC Neurol. 2010;10:87.

170. Cipriani G, Carlesi C, Lucetti C, Danti S, Nuti A. Eating behaviors and dietary changes in patients with dementia. Am J Alzheimers Dis Other Demen. 2016;31(8):706-16.

171. Hwang JP, Yang CH, Tsai SJ, Liu KM. Behavioural disturbances in psychiatric inpatients with dementia of the Alzheimer's type in Taiwan. Int J Geriatr Psychiatry. 1997;12(9):902-6.

172. Adebakin A, Bradley J, Gumusgoz S, Waters EJ, Lawrence CB. Impaired satiation and increased feeding behaviour in the tripletransgenic Alzheimer's disease mouse model. PLoS One. 2012;7 (10): e45179.

173. Bhagavati S. Marked hyperphagia associated with total loss of satiety in Alzheimer's disease. J Neuropsychiatry Clin Neurosci. 2008;20(2):248-9.

174. Burns A, Jacoby R, Levy R. Psychiatric phenomena in Alzheimer's disease. IV: Disorders of behaviour. $\mathrm{Br} \mathrm{J}$ Psychiatry. 1990;157:86-94.

175. Tsang SW, Keene J, Hope T, et al. A serotoninergic basis for hyperphagic eating changes in Alzheimer's disease. J Neurol Sci. 2010;288(1-2):151-5.

176. Gardener S, Gu Y, Rainey-Smith SR, et al. Adherence to a Mediterranean diet and Alzheimer's disease risk in an Australian population. Transl Psychiatry. 2012;2:e164.

177. Tombini M, Sicari M, Pellegrino G, Ursini F, Insarda P, Di Lazzaro V. Nutritional status of patients with Alzheimer's disease and their caregivers. J Alzheimers Dis. 2016;54(4):1619-27.

178. Sun J, Wen S, Zhou J, Ding S. Association between malnutrition and hyperhomocysteine in Alzheimer's disease patients and diet intervention of betaine. J Clin Lab Anal. 2017;31(5): e22090.

179. Sparre-Sorensen M, Kristensen G. Alzheimer's disease in the Danish malnutrition period 1999-2007. J Alzheimers Dis. 2015;48(4):979-85.

180. Yildiz D, Buyukkoyuncu Pekel N, Kilic AK, Tolgay EN, Tufan F. Malnutrition is associated with dementia severity and geriatric syndromes in patients with Alzheimer disease. Turk J Med Sci. 2015;45(5):1078-81

181. Walter-Sack I, Klotz U. Influence of diet and nutritional status on drug metabolism. Clin Pharmacokinet. 1996;31(1):47-64.

182. Tan KK, Trull AK, Uttridge JA, et al. Effect of dietary fat on the pharmacokinetics and pharmacodynamics of cyclosporine in kidney transplant recipients. Clin Pharmacol Ther. 1995;57(4):425-33. 
183. Gupta SK, Benet LZ. High-fat meals increase the clearance of cyclosporine. Pharm Res. 1990;7(1):46-8.

184. Krishnaswamy K. Drug metabolism and pharmacokinetics in malnourished children. Clin Pharmacokinet. 1989;17(Suppl 1):68-88.

185. Speerhas R. Drug metabolism in malnutrition and obesity: clinical concerns. Cleve Clin J Med. 1995;62(1):73-5.

186. Morgan ET. Impact of infectious and inflammatory disease on cytochrome P450-mediated drug metabolism and pharmacokinetics. Clin Pharmacol Ther. 2009;85(4):434-8.

187. Renton KW. Regulation of drug metabolism and disposition during inflammation and infection. Expert Opin Drug Metab Toxicol. 2005;1(4):629-40.
188. Farlow MR, Grossberg GT, Sadowsky CH, Meng X, Somogyi M. A 24-week, randomized, controlled trial of rivastigmine patch $13.3 \mathrm{mg} / 24 \mathrm{~h}$ versus $4.6 \mathrm{mg} / 24 \mathrm{~h}$ in severe Alzheimer's dementia. CNS Neurosci Ther. 2013;19(10):745-52.

189. Yatabe Y, Hashimoto M, Kaneda K, et al. Efficacy of increasing donepezil in mild to moderate Alzheimer's disease patients who show a diminished response to $5 \mathrm{mg}$ donepezil: a preliminary study. Psychogeriatrics. 2013;13(2):88-93.

190. Popik P, Kos T, Zhang Y, Bisaga A. Memantine reduces consumption of highly palatable food in a rat model of binge eating. Amino Acids. 2011;40(2):477-85.

191. Shim JS, Oh K, Kim HC. Dietary assessment methods in epidemiologic studies. Epidemiol Health. 2014;36:e2014009. 